\title{
Controlling the immunological crosstalk during conception and pregnancy: HLA-G in reproduction
}

\section{Line Lynge Nilsson ${ }^{\dagger}$, Snezana Djurisic ${ }^{\dagger}$ and Thomas Vauvert F. Hviid *}

Centre for Immune Regulation and Reproductive Immunology, Department of Clinical Biochemistry, Copenhagen University Hospital, Roskilde, Denmark

\section{Edited by:}

Sinuhe Hahn, University Clinics Basel, Switzerland

\section{Reviewed by:}

Silvia Gregori, San Raffaele Telethon Institute for Gene Therapy, Italy

Daisuke Kamimura, Osaka University, Japan

Heinz Hutter, Medical University of Graz, Austria

*Correspondence:

Thomas Vauvert F. Hviid, Centre for Immune Regulation and Reproductive Immunology (CIRRI), Department of Clinical Biochemistry, Copenhagen

University Hospital, Roskilde Hospital, 7-13 Køgevej, Roskilde DK-4000,

Denmark

e-mail: tvh@regionsjaelland.dk

${ }^{\dagger}$ Line Lynge Nilsson and Snezana Djurisic have contributed equally to this work.
In several years after its discovery in the placenta, the human leukocyte antigen (HLA) class lb protein, HLA-G, was not given much attention, nor was it assigned great importance. As time has unraveled, HLA-G has proven to have distinctive functions and an unforeseen and possibly important role in reproduction. HLA-G is characterized mainly by its low polymorphism and restricted tissue distribution in non-pathological conditions. In fact, its expression pattern is primarily limited to extravillous cytotrophoblast cells at the maternalfetal interface during pregnancy. Due to low polymorphism, almost the same protein is expressed by virtually all individuals. It is these unique features that make HLA-G differ from its highly polymorphic HLA class la counterparts, the HLA-A, $-B$, and $-C$ molecules. Its function, seemingly diverse, is typically receptor-mediated, and involves interactions with a wide range of immune cells. As the expression of HLA-G primarily is limited to gestation, this has given rise to the hypothesis that HLA-G plays an important role in the immunological tolerance of the fetus by the mother. In keeping with this, it might not be surprising that polymorphisms in the HLA-G gene, and levels of HLA-G expression, have been linked to reproductive failure and pre-eclampsia. Based on recent studies, we speculate that HLA-G might be involved in mechanisms in reproductive immunology even before conception because HLA-G can be detected in the genital tract and in the blood of non-pregnant women, and is present in seminal fluid from men. In addition, HLA-G expression has been found in the pre-implanted embryo. Therefore, we propose that a combined contribution from the mother, the father, and the embryo/fetus is likely to be important. Furthermore, this review presents important aspects of HLA-G in relation to reproduction: from genetics to physiological effects, from pregnancy and pregnancy complications to a short discussion on future possible means of preventative measures and therapy.

Keywords: MHC, HLA class Ib, HLA-G, human reproduction, pregnancy complications

\section{INTRODUCTION}

The uterus and the placenta constitute a unique site of immune modulation where the semi-allogeneic fetus is tolerated by the maternal immune system. Both the mother and the fetus contribute to maintenance of tolerance. The mother through the presence of local regulatory immune cells that regulate redundant immune responses and the fetus, possibly among several mechanisms, through expression of non-classical human major histocompatibility complex (MHC) class Ib molecules, human leukocyte antigen (HLA)-E, -F, and -G, on extravillous trophoblast cells that infiltrate the decidua and make a direct contact with maternal immune cells (1-3). To the best of our knowledge, a classical antigen-presenting function, or capacity, of HLA-G has never been described, although the HLA-G molecule can bind peptides (4).

The expression of HLA-G is primarily limited to gestation and it has been widely studied in pregnancy because of its association with pregnancy complications, in particular pre-eclampsia and recurrent miscarriages $(2,5-8)$. The expression of HLA-G by embryos, as well as in the presence of soluble HLA-G (sHLA-G) in the maternal circulation, is associated with better pregnancy rates $(9,10)$. Furthermore, a different, possible role of HLA-G has been proposed in the context of remodeling of spiral arteries during placental development (11). However, further studies are needed to confirm this.

An accumulating body of evidence suggests that HLA-G may be an important factor in reproduction even before conception. sHLA-G circulates in the blood of non-pregnant women (and in the blood of male donors), HLA-G is expressed in the female genital tract, and sHLA-G has been identified in seminal plasma (Figure 1) (12-16). In addition, HLA-G expression has been found in the pre-implanted embryo. Thereby, a combined contribution from the mother, the father, and the embryo, or fetus, is likely to be important. The aim of the present review is to give an overview of, and to discuss, important aspects of HLA-G in relation to reproduction: from genetics to physiological effects, from pregnancy and pregnancy complications to a short discussion on future possible means of preventative measures and therapy.

\section{THE HLA-G GENE}

\section{HLA-G POLYMORPHISMS IN CODING REGIONS}

The HLA-G gene contains eight exons and seven introns (Figure 2). The external part of the HLA-G molecule consists of three parts, the $\alpha 1, \alpha 2$, and $\alpha 3$ domains (exons $2-4$ ). The HLA-G 


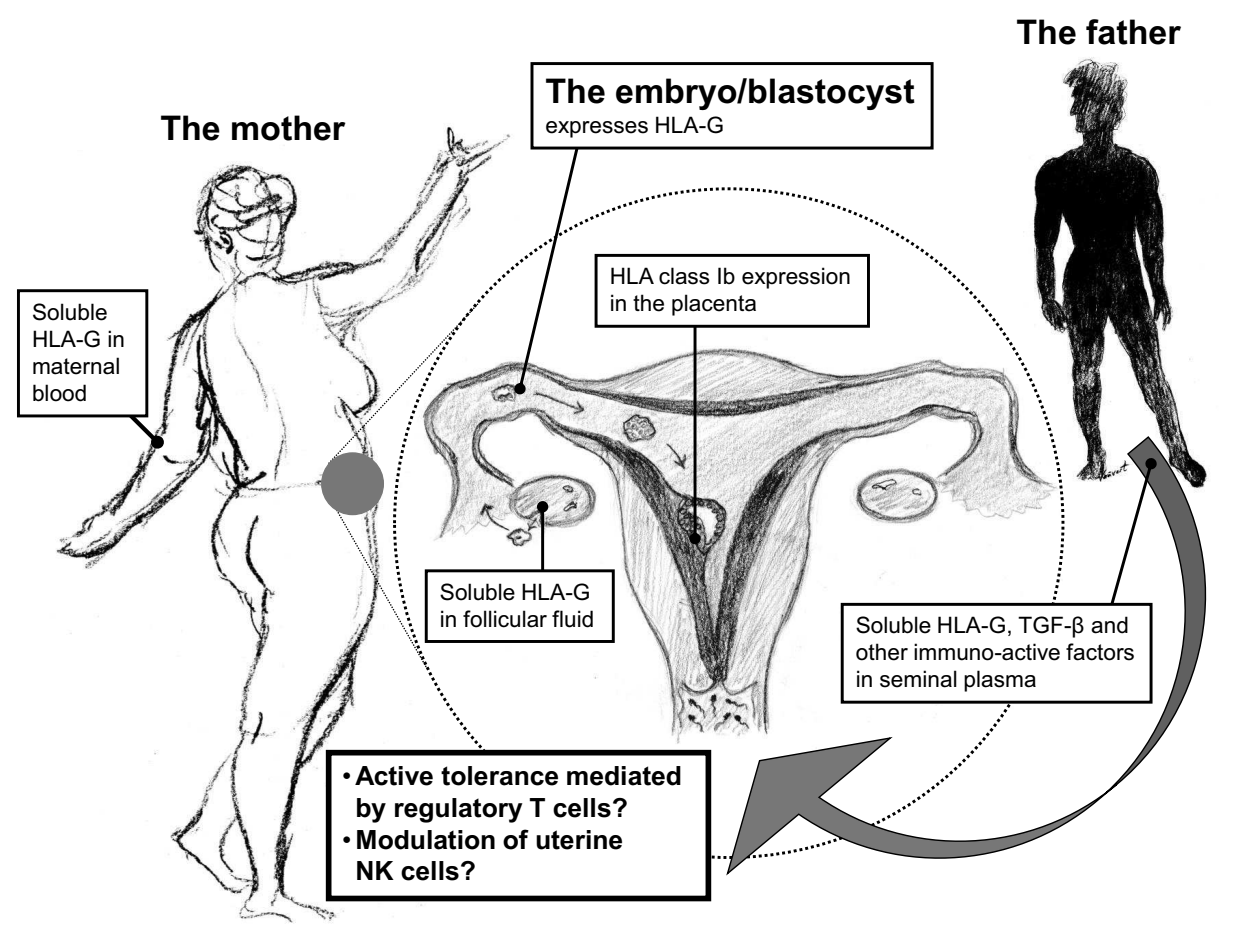

FIGURE 1 | An important and central role of HLA-G in reproduction may be depicted from its wide distribution within the reproductive cycle. HLA-G is expressed in maternal blood, in follicular fluid, and in seminal plasma prior to implantation, and after fertilization in the blastocyst/embryo and in the placenta by the trophoblast cells. The continuous expression of HLA-G in the reproductive cycle may in particular modulate local immune cells in the female reproductive system for immunological acceptance of the semi-allogenic embryo.

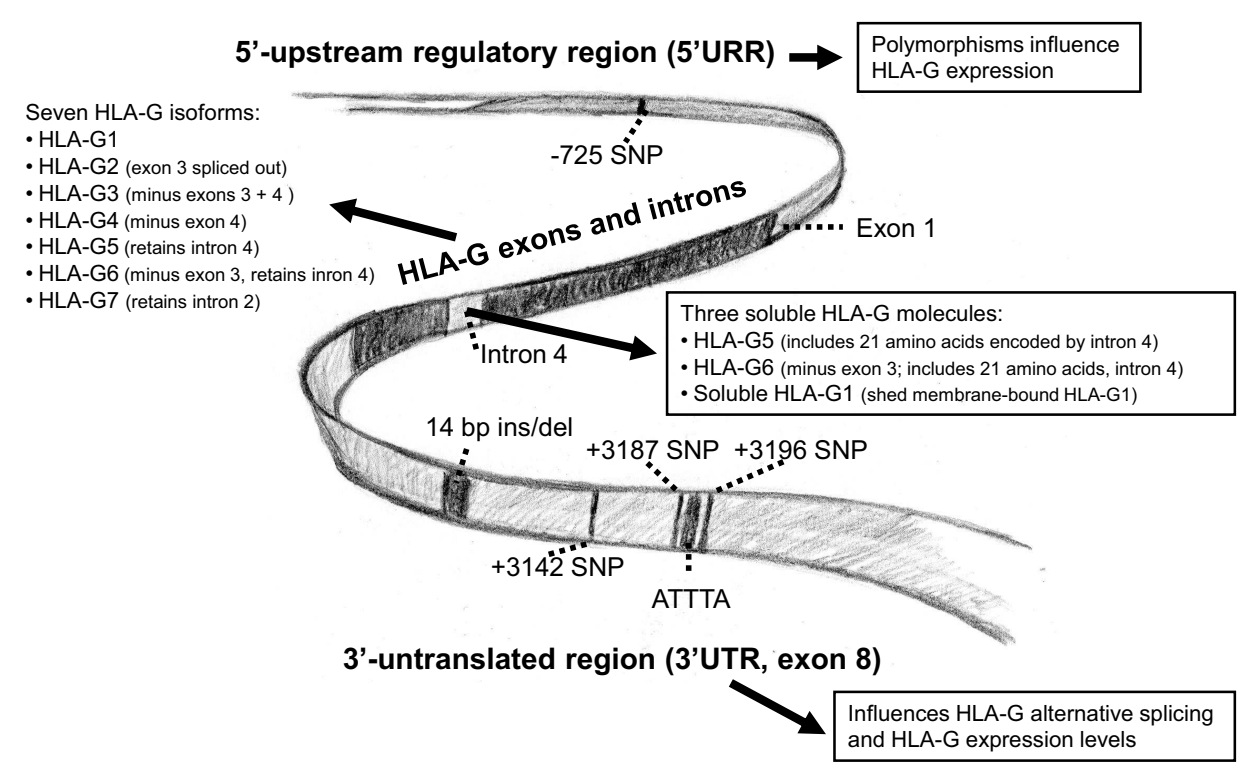

\section{The Human Leukocyte Antigen-G gene}

FIGURE 2 |A schematic representation of the HLA-G gene. Some of the most intensively studied gene polymorphisms in the $5^{\prime}$-upstream regulatory region and in the 3'-untranslated region. An overview of the different HLA-G isoforms is included. 
full-length membrane protein is anchored in the cell membrane by the transmembrane region (exon 5 ). The cytoplasmic domain is encoded by exon 6 and the very first, short part of exon 8 (3, 17). Polymorphisms in the coding region of $H L A-G$ are relatively scarce but evenly distributed between exons 2,3 , and 4 , as well as in introns $(6,7,18-20)$. Most polymorphisms do not alter the protein sequence, and the ones that do, allow for a grouping in major allele groups: $G^{\star} 01: 01: x x: x x, G^{\star} 01: 01: x x, G^{\star} 01: 02$, $G^{\star} 01: 03: x x: x x, G^{\star} 01: 04: x x, G^{\star} 01: 05 N$ (null allele), $G^{\star} 01: 06$, and $G^{\star} 01: 07$ to $G^{\star} 01: 18$. However, polymorphisms that define these allele groups have probably no effect on the secondary structures of the heavy chains, and the functional relevance of this nucleotide variability remains unclear. In total, 50 alleles and 16 allele groups representing an amino acid substitution have been described in the HLA-G gene sequence [WHO Nomenclature Committee for Factors of the HLA System and the International Immunogenetics Information System (IMGT)/HLA Database].

The polymorphic deletion of the first basepair (bp) of codon 130 or the third of codon 129 , which results in a frameshift, defines the null allele $\left(G^{*} 01: 05 N\right)$, and this null allele does not encode functional full-length HLA-G protein isoforms (HLA-G1 and-G5, see below) $(18,21)$. Nonetheless, studies show that these isoforms are not essential for fetal survival, indicating that expression of other HLA-G isoforms or HLA-E and/or -F, which are also involved in immune modulation in the placenta, may compensate for the lack of HLA-G1 and -G5 protein (22-24).

\section{HLA-G POLYMORPHISMS IN NON-CODING REGIONS}

The functional mRNA level of $H L A-G$ is governed by the rate of synthesis, mainly driven by the promoter region, or $5^{\prime}$-upstream regulatory region $\left(5^{\prime}-\mathrm{URR}\right)$, as well as by the rate of degradation, stability, localization, and translation of the mRNA (25) (Figure 2). The rate at which pre-mRNA is produced is partly mediated by pre-transcriptional events, e.g., binding of transcription factors to regulatory motifs in the promoter region. HLA class I promoters sequences are generally conserved, but the HLA-G promoter is somewhat unique. Although its nucleotide sequence and structure is similar to other class I genes in several aspects, peculiarly, most regulatory motifs in the HLA-G promoter region are nonfunctional (20). Of importance, two main regulatory modules are flawed. First, the interferon (IFN)/Enhancer A region is blemished by a 16-bp deletion $(17,26)$, and second, the SXY module that mounts the transcriptional apparatus, represents a divergent sequence that does not allow for appropriate binding of the class II transactivator (CIITA) (27).

The $3^{\prime}$-untranslated region $\left(3^{\prime} \mathrm{UTR}\right)$ of the $H L A-G$ gene also exhibits several regulatory elements including AU-rich motifs and a poly-A signal to influence mRNA stability, turnover, mobility, and splicing pattern $(20,28)$. Polymorphisms in these regions may thus affect the expression of HLA-G by altered regulation of gene transcription or by destabilizing the mRNA transcript (28-30). Indeed, several important polymorphisms have been described in the $5^{\prime}$ URR and the $3^{\prime}$ UTR of the HLA-G gene (28, 29, 31-34).

\section{THE $5^{\prime}$-UPSTREAM REGULATORY REGION OF THE HLA-G GENE}

Polymorphisms in the HLA-G 5'URR are close to regulatory elements and $\mathrm{CpG}$ sites, and are likely to alter binding of transcription factors and/or promoter methylation, and as a consequence influence the rate of transcription. Although sequence variation affecting transcription would be expected inside regulatory elements, most variable sites are not found in known motifs (20). Interestingly, an accumulating body of evidence indicates a balancing selection on the HLA-G promoter, and thereby indicates a preference for heterozygosity in which, possibly, individuals with both high- and low-expressing promoters are privileged (19, 29, 33, 35). Few studies address the direct association between HLA-G promoter SNPs and a differential HLA-G expression. One variation, a SNP at position - 725 (rs123334), is associated with sporadic miscarriages and differential HLA-G expression $(32,36)$, and others, SNPs at position $-1305,-964$, and -486 , are associated with yet other conditions like vitiligo, asthma, and acute allograft rejection in end-stage renal disease (37-39).

\section{THE 3' UNTRANSLATED REGION OF THE HLA-G GENE}

In contrast to the coding region, the $3^{\prime} \mathrm{UTR}$ of the $H L A-G$ locus presents a rather high degree of variation. Since the $3^{\prime} \mathrm{UTR}$ of the $H L A-G$ gene exhibits several regulatory elements including AUrich motifs, a poly-A signal, as well as signals that regulate the spatial and temporal expression of mRNA, the polymorphic sites may influence mRNA stability, turnover, mobility, and splicing pattern $(20,28,30)$. A 14-bp ins/del (rs66554220) located in exon 8 is the best studied polymorphism in the $3^{\prime} \mathrm{UTR}$, and has been shown to influence HLA-G mRNA transcript size and stability (19, $28,30,31,40-42)$. The presence of the 14-bp-insertion sequence introduces an alternative splice site that generates a 92-bp deletion in the $3^{\prime} \mathrm{UTR}$ of the $H L A-G$ mRNAs, and this alternative splice form seems to have an impact on the expression levels of HLA-G $(5,28,40,41)$. The positions of polymorphism in the $3^{\prime} \mathrm{UTR}$ of the $H L A-G$ gene are in the current review numbered according to the publication by Castelli et al., which includes the 14-bp sequence in the reference sequence (43). At least three other SNPs in the $3^{\prime} \mathrm{UTR}$ are associated with $H L A-G$ mRNA regulation and differences in sHLA-G levels: one positioned at +3142 (rs1063320) substituting a $\mathrm{C}$ to a $\mathrm{G}$, another at +3187 (rs9380142) substituting an A to a $\mathrm{G}$, and the third at position +3196 (rs1610696) where a $C$ is substituted with a $\mathrm{G}$ (Figure 2). Studies show that polymorphisms in the $3^{\prime}$ UTR probably act as targets for microRNAs, thereby controlling $H L A-G$ mRNA stability and expression levels $(8,43-47)$. Furthermore, the +3187 and the +3196 SNPs are located just before and after an AUUUA motif associated with mRNA stability $(28,43)$.

\section{COMBINED 5'URR AND 3'UTR HLA-G HAPLOTYPES}

In some cases, polymorphism in the $H L A-G 5^{\prime} \mathrm{URR} /$ promoter region may be in linkage disequilibrium with $H L A-G 3^{\prime}$ UTR variants $(19,33,37)$, and some of them might influence alternative splicing and mRNA stability $(30,48)$. The -725 SNP located in the $5^{\prime} \mathrm{URR}$ is possibly in linkage disequilibrium with the 14-bp ins/del, the +3142 , and the +3187 polymorphic sites, and is suggested to influence the stability of mRNA transcripts (36). Recently, the full combinations of 5'URR haplotypes, HLA-G WHO nomenclature alleles, and $3^{\prime}$ UTR haplotypes in the HLA-G gene have been elucidated in a Brazilian population (33). The DNA polymorphisms in these extended $H L A-G$ haplotypes may influence $H L A-G$ expression and the stability of HLA-G mRNA transcripts in combination. 
Investigating the 5'URR and $3^{\prime}$ UTR $H L A-G$ extended haplotypes instead of evaluating single polymorphisms could determine the significance of allelic variants of $H L A-G$ more accurately (33). A study correlating $3^{\prime}$ UTR extended haplotypes with HLA-G soluble levels in a Brazilian and French cohort, showed that some haplotypes were associated with high sHLA-G levels (named UTR-1) and some with low sHLA-G levels in blood plasma from healthy donors (named UTR-5 and UTR-7) (47). However, full consensus does not exist in these studies, as another French study reported conflicting results (46). These different HLA-G haplotypes differ at the 14-bp ins/del, the +3142 , the +3187 , and the +3196 polymorphic sites in the $3^{\prime} \mathrm{UTR}$, as well as in polymorphic sites in the 5'URR.

\section{UNIOUE CHARACTERISTICS OF HLA-G}

A characteristic unique to HLA-G is the post-transcriptional alternative splicing of the mRNA from the single HLA-G gene. HLA-G1 represents the full-length isoform, whereas the other isoforms are formed by out-splicing of exons. This result in seven isoforms, four of which are membrane-bound (HLA-G1, HLA-G2, HLA-G3, and HLA-G4), and three of which are soluble (sHLA-G5, sHLA-G6, and sHLA-G7) $(40,49,50)$ (Figure 2). HLA-G1 and HLA-G5 are the most studied isoforms. In contrast to other HLA class I genes, exon 6 of the $H L A-G$ gene encodes a pre-mature stop codon that results in a truncated cytoplasmic tail (17). The truncated cytoplasmic tail results in a reduced endocytosis and thus a low cell surface turnover of the HLA-G molecule $(51,52)$. The soluble isoforms lack the transmembrane region due to a stop codon in intron 4 $(40,50)$. In the presence of metalloproteinases, HLA-G1 loaded with peptide can be shed from the surface by proteolytic cleavage, also resulting in a soluble molecule. HLA-G1 and sHLA-G5 are both capable of forming heterodimers with $\beta 2$-microglobulin ( $\beta 2 \mathrm{~m})$ (53).

\section{HLA-G EXPRESSION AND FUNCTION IN RELATION TO REPRODUCTION}

We propose that HLA-G might be involved in mechanisms in reproduction even before conception because HLA-G can be detected in the genital tract and in the blood of non-pregnant women, and is present in seminal fluid from men.

The function of HLA-G seems to be diverse, involving interactions with NK cells, cytotoxic T lymphocytes, regulatory $\mathrm{T}$ cells (Tregs), and it may be involved in regulating angiogenesis and cell migration (Figure 3). HLA-G is expressed by the extravillous trophoblast cells in the placenta, where the molecule has been attributed an important role in early placentation and maintenance of successful pregnancy $(2,3)$. Also, HLA-G is expressed in tissues important for the reproductive cycle. HLA-G is expressed in the

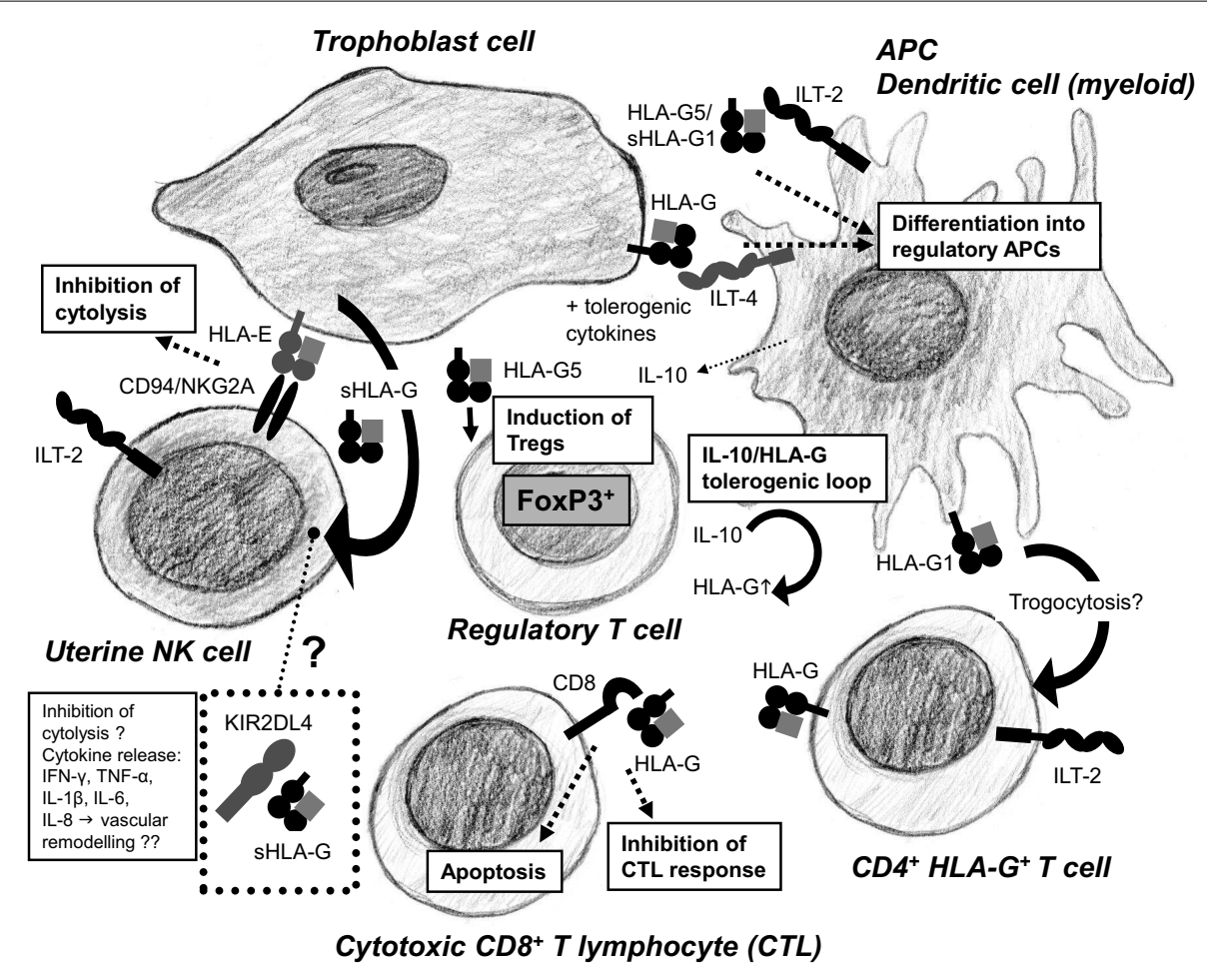

FIGURE 3 | Human leukocyte antigen-G is a key mediator of the tolerogenic loop arising from the crosstalk between immune cells in the placenta. HLA-G promotes differentiation of DCs into tolerogenic DCs secreting IL-10, TGF- $\beta$, and expressing HLA-G. IL-10 and TGF- $\beta$ induce Tregs. Tregs stimulate trophoblast cells to further upregulate expression of HLA-G. HLA-G can be acquired by $\mathrm{CD} 4^{+} \mathrm{T}$ cells through trogocytosis, increasing the pool of regulatory immune cells in the placenta. Cytotoxic
$\mathrm{CD} 8^{+} \mathrm{T}$ cells are inactivated and undergo apoptosis by binding of HLA-G to the CD8 co-receptor. HLA-E presents HLA-G derived signal peptides and bind to the CD94/NKG2A receptors on uterine NK cells inhibiting cytotoxicity. Soluble HLA-G from trophoblast cells accumulates in $\mathrm{KIR} 2 \mathrm{DL} 4^{+}$endosomes in uterine NK cells, which may result in active secretion of proangiogenic and proinflammatory cytokines, although this is controversial. 
follicular fluid and in the genital tract $(15,54,55)$. Furthermore, HLA-G and sHLA-G has been detected in the male reproductive system and in semen $(14,56)$. After fertilization, HLA-G is expressed by the blastocyst and the early embryo $(57,58)$. HLA$G$ is also expressed at other immune privileged sites such as the cornea and thymic epithelial cells $(59,60)$. Finally, sHLA-G can be measured in peripheral blood from healthy female and male donors, and during pregnancy the concentration raises two to five times compared to what is observed in non-pregnant women (9, $12,61,62)$. One of the sources of soluble HLA-G5 in the blood of non-pregnant women and in men is most likely monocytes; though $\mathrm{CD}^{+}$and $\mathrm{CD} 8^{+} \mathrm{T}$ cells and $\mathrm{B}$ cells seem to be able to secrete HLA-G5 as well, although in lower amounts (63). However, during pregnancy a substantial amount of sHLA-G may be derived from the placenta by shed HLA-G1 and possibly secreted HLA-G5. sHLA-G levels in blood are associated with HLA-G gene polymorphisms and HLA-G haplotypes $(19,64)$.

The blastocyst implants into the uterine wall and the fetalderived extravillous trophoblast cells invade the decidua and are involved in the remodeling of the spiral arteries. The maternal blood flow and tissue leukocytes are hence in direct contact with fetal trophoblast cells that express HLA-G $(2,65)$.

Still, it seems to be controversial, whether or not the soluble HLA-G5 and -G6 isoforms are secreted by trophoblast cells (66). Nonetheless, first trimester trophoblast expresses HLA-G5 and -G6 mRNA transcripts (28). One study has suggested that the major sHLA-G isoform in maternal serum should be HLA-G6 (or soluble HLA-G2) only consisting of heavy chains (67). However, to our knowledge these results have not been reproduced.

\section{REGULATION OF HLA-G EXPRESSION}

The regulation of HLA-G expression has been studied on different levels, and the majority of studies have focused on the importance of the genetic polymorphisms in the HLA-G gene as previously mentioned. Especially the 14-bp ins/del polymorphism in the $3^{\prime} \mathrm{UTR}$, exon 8, of the HLA-G gene has been implicated in mRNA stability and hence the overall HLA-G production. However, conflicting reports on whether the 14-bp-insertion allele is associated with high or low level of expression of HLA-G exist. Experiments with HLA-G transductants showed that K562 cells with the $3^{\prime}$ UTR 14 bp-insertion sequence had more stable mRNA compared to transductants lacking the 14-bp insertion. The study also looked at the functional impact of the 14-bp insertion on NK cell cytotoxicity, and found that K562 transductant cells carrying the 14-bp-insertion sequence were significantly less sensitive to NK cell cytotoxicity as compared to K562 cells that did not carry the 14-bp-insertion sequence (42). However, this study only investigated the isolated role of the 14-bp sequence in experiments performed with the use of a cell line, and the importance of the 14-bp-insertion sequence may be modulated or influenced by other linked polymorphisms in the $3^{\prime} \mathrm{UTR}$, and in future studies it is important to study different $H L A-G$ haplotypes. A study by Martelli-Palomino et al. showed that the 14-bp deletion allele correlated with higher blood plasma sHLA-G levels compared to the 14-bp insertion in extended 3'UTR HLA-G haplotypes (47). This is in line with previous studies, which have shown that the 14-bp ins/14 bp ins HLA-G genotype is associated with lower blood plasma and serum sHLA-G levels, compared to the 14bp del/14 bp ins genotype and the 14-bp del/14 bp del genotype $(12,13)$. MicroRNAs have also been shown to regulate HLA-G expression and thereby function. In a study by Manaster et al., two microRNAs, miR-148a and miR-152 were shown to downregulate HLA-G expression and thereby reduce the binding of HLA-G to its cognate inhibitory receptor immunoglobulin-like transcript 2 (ILT-2). And interestingly, in the placenta, the cellular content of miR-148a and miR-152 shown to reduce HLA-G expression was very low compared to other tissues. Therefore, it can be speculated that this might be one of the reasons for high tissue restricted expression in the placenta (45). The HLA-G suppression by miR-152 in JEG-3 cells, followed by increased susceptibility to NK cell-mediated cytolysis, has also been shown in a previous study (68). Soluble factors, like immune-modulatory hormones and cytokines have shown to influence the transcription of HLA-G. The rate of HLA-G transcription is increased by the cytokine IFN- $\beta$. The indoleamine 2,3-dioxygenase (IDO), which is an enzyme catabolizing tryptophan, has shown to increase the shedding and expression of HLA-G in myeloid dendritic cells (DCs), which contribute to a tolerogenic milieu (69). In fact, IDO has shown to promote maternal tolerance toward the fetus by catabolizing tryptophan and thereby suppressing the $\mathrm{T}$ cell activity in mice (70).

The acquirement of HLA-G by HLA-G-negative cells has been shown to be possible via trogocytosis. This mechanism is characterized by the transfer of surface molecules from one cell to another through cell-cell contact. Activated $\mathrm{CD} 4^{+}$and $\mathrm{CD} 8^{+} \mathrm{T}$ cells can acquire HLA-G from antigen-presenting cells (APCs) through this mechanism and thus contribute to an immune suppressive milieu without expressing HLA-G themselves, but only temporarily displaying it (71).

The trophoblast cells have an alternative HLA expression profile compared to all other cells in the human body, in that they only express the non-classical MHC class Ib (HLA-E, -F, and -G) molecules, and to some extend the classical MHC class Ia HLAC. Usually, an altered HLA expression profile is associated with a pathological condition, such as a virus infection or in malignant transformation, and thus induces an immune response mediated by the engagement and cytolytic killing of the cell in question by NK cells. HLA-G, however, engages inhibitory molecules on leukocytes rendering them anergic toward the trophoblast cells, thereby protecting the allogeneic fetus $(2,65,72)$. HLA-G interacts with the ILT-2 and ILT-4 receptors, the co-receptor CD8, and maybe the killer cell immunoglobulin-like receptor (KIR) 2DL4 (73).

\section{THE HLA-G RECEPTORS}

The uterine NK (uNK) cells, identified by being CD16 ${ }^{-} \mathrm{CD} 56^{\text {bright }}$, as opposed to peripheral $\mathrm{CD} 16^{+} \mathrm{CD} 56^{+} \mathrm{NK}$ cells, express KIR2DL4, which is described as a receptor for HLA-G, although a recent study has made this controversial $(74,75)$. KIR2DL4 has an immunoreceptor tyrosine-based inhibitory motif (ITIM) at its cytoplasmic tail, and is characterized by its expression in endosomes. Despite having an ITIM, KIR2DL4 when possibly bound to HLA-G shows weak inhibition of uNK cell. Because of its endosomal expression, at least in steady state conditions, KIR2DL4 seems to bind sHLA-G, which may activate the uNK cell to secrete 
cytokines and chemokines important for angiogenesis (76). However, further studies are certainly needed to clarify the possible interactions between HLA-G and KIR2DL4.

Immunoglobulin-like transcript 2 and ILT-4 are inhibitory receptors expressed on leukocytes. These receptors also bind other HLA class I molecules, however, preferentially bind HLA-G (77). ILT-2 and ILT-4 contain three ITIMs at their cytoplasmic tail. ILT2 (also named LILRB1) is expressed by monocytes, macrophages, $\mathrm{CD}^{+}{ }^{+}$and $\mathrm{CD}^{+}{ }^{+} \mathrm{T}$ cells, B cells, and myeloid DCs and engages only heterodimers of HLA-G1 or sHLA-G5 and $\beta 2 \mathrm{~m}$. ILT-4 (LILRB2) expressed by monocytes, macrophages, and myeloid DCs can also interact with HLA-G monomers. The discrepancy in HLA-G interaction with ILT-2 and ILT-4 has been clarified with the use of crystal structures showing that ILT-2 cannot recognize the $\beta 2 \mathrm{~m}$-free form of HLA-G, whereas ILT- 4 preferably bind the $\alpha 3$ domain of the HLA-G heavy chain (78). In fact, by binding to its cognate inhibitory receptors, HLA-G has shown to up-regulate the expression of ILT-2 and ILT-4. The functional consequence of inhibitory receptor up-regulation by HLA-G was hypothesized to be an increased sensitivity toward inhibition mediated, not only by HLA-G, but also by classical HLA class I molecules known to bind ILT-2 and ILT-4 (79). The co-receptor CD8 expressed on cytotoxic T cells is also known to bind HLA-G. This interaction causes apoptosis of the activated $\mathrm{CD}^{+} \mathrm{T}$ cells mediated by the FAS ligand/FAS pathway (80).

\section{HLA-G IN REPRODUCTIVE IMMUNOLOGY}

Cell-cell interactions between leukocytes and trophoblast cells mediated by HLA-G and its above-mentioned receptors are of great interest in order to understand the immune regulation at the feto-maternal interface (Figure 3). So far, several studies have tried to elucidate the strict immune regulation taking place at this anatomical site. A range of different studies indicate that HLA$G$ might have a central position in the immune regulation at conception and during pregnancy.

\section{NK CELLS, DCs, AND T CELLS}

It has become clear that DCs and T cells, especially Tregs, in the decidua are important contributors to the tolerogenic milieu in pregnancy and several studies have described such cells and their implications in healthy and in complicated pregnancies. Some of the described cell types have overlapping features. However, the NK cells are by far the most abundant cells in the uterus.

The early decidua is characterized by an abundance of uterine $\mathrm{CD} 16^{-/ \mathrm{dim}} \mathrm{CD} 56^{\text {bright }} \mathrm{NK}$ cells that are in close contact with the fetal-derived extravillous trophoblast cells. uNK cells possess ILT-2, ILT-4, and KIR2DL4 receptors that bind HLA-G expressed on the surface of the infiltrating trophoblast cells. The CD $16^{-/ \text {dim }}$ CD56 ${ }^{\text {bright }} \mathrm{NK}$ cells are the largest population of lymphocytes in the uterus, they constitute $50-90 \%$ of lymphocytes in human uterine decidua in early pregnancy. They are phenotypically and functionally distinct from conventional CD $16^{+} \mathrm{CD} 56^{\mathrm{dim}}$ NK cells that circulate the periphery (81). They are recruited in large numbers through the first and second trimester and participate in the modification of the uterine spiral arteries, which increases blood flow to the fetus (82). The crosstalk between DCs and NK cells has been shown to be modulated by sHLA-G in cell cultures. DCs cultured with sHLA-G showed a reduced ability to induce NK cell activation (83). HLA-G non-amers have shown to be presented by HLA-E, which stabilizes the HLA-E molecule (84).

Gregori et al. have shown that a specialized tolerogenic type of DCs is accumulating in the human decidua during pregnancy. These cells express HLA-G and are named DC-10 because they secrete high amounts of IL-10. DC-10 can induce type 1 regulatory $\mathrm{T}(\operatorname{Tr} 1)$ cells, which are characterized by their cytokine profile - secretion of IL-10 and TGF- $\beta$ among others $(73,85)$.

Thymic stromal lymphopoietin (TSLP) is expressed by the epithelial cells of Hassall's corpuscles in the thymus and induce DCs to stimulate Treg differentiation. During pregnancy though, the function of the thymus is reduced, and the Treg expansion during pregnancy has been proposed to take place in the placenta since TSLP is produced by the trophoblast cells. The trophoblast cells are in close contact with DCs around the spiral arteries and TSLP likely activate the CD11 ${ }^{+}$DCs to secrete IL-10 and TGF- $\beta$ and instructing them to induce the differentiation of immature $T$ cells into $\mathrm{CD} 4{ }^{+} \mathrm{CD} 25^{+} \mathrm{FoxP}^{+}$Tregs that also secrete IL- 10 and TGF- $\beta$. The Tregs further induce the trophoblast cells to express HLA-G, which causes the decrease in uNK cytotoxicity. This tolerogenic loop was recently described by Du et al. (86). The DCs in the study by Du et al. secreted IL-10 as well as the HLA-G-expressing DC-10 described by Gregori et al. and it can be speculated if they might be part of the same DC subset. Also, HLA-G presenting CD4 ${ }^{+} \mathrm{T}$ cells have been identified at the feto-maternal interface, where they may contribute to the tolerogenic milieu (87).

In mice, it has been shown that the overall $\mathrm{CD} 4{ }^{+} \mathrm{CD} 25^{+}$suppressive $\mathrm{T}$ cell pool increases during pregnancy, that a third of the $\mathrm{CD}^{+}{ }^{+} \mathrm{CD} 25^{+} \mathrm{T}$ cells in the pregnant uterus express FoxP3, and that depletion of CD25 $5^{+} \mathrm{T}$ cells results in gestation failure (88).

\section{HLA-G POLYMORPHISMS IN PRE-ECLAMPSIA AND RECURRENT MISCARRIAGES}

Pre-eclampsia is a multisystemic pregnancy disorder that is manifested clinically in the late second and third trimester of pregnancy. The etiology of pre-eclampsia is unknown, although a substantial number of studies favor a theory based on a maladapted immune system, with the more specific attributes of low levels of immune regulatory cells and a low expression of HLA-G. The low expression is hypothesized partly to be a consequence of genetic variability. In support of this, a reduced level of $H L A-G$ mRNA is observed in pre-eclamptic placentas, which directly correlates with the HLA-G genotype (5). Especially, the 14-bp ins/del 3'UTR polymorphism in exon 8 has been extensively studied, and this polymorphism has been found to be associated with severe preeclampsia in several studies $(5,6,8,89,90)$. However, some studies have not observed an association between the 14-bp ins/del polymorphism and pre-eclampsia (91-93). Few studies address the issue that pre-eclampsia presents in a mild and a severe form, and furthermore, that it can be defined based on early- and late-onset, and importantly, that these forms potentially have distinct etiologies (94). Other polymorphisms associated with pre-eclampsia are typically present in the $5^{\prime} \mathrm{URR}$ and $3^{\prime} \operatorname{UTR}(8,95)$.

HLA-G polymorphisms have been investigated in relation to recurrent miscarriages, also, with contradicting results (64, 96, 97). Two meta-analysis have addressed the possible association 
between the 14-bp ins/del and recurrent miscarriages: the first performed by Wang et al. including 14 studies, 1464 cases, and 1247 controls, found that the 14-bp ins/del is significantly associated with unexplained recurrent miscarriage, and suggests that the 14bp-insertion increases the risk of recurrent miscarriage (98). These findings were challenged by another meta-analysis performed by Fan et al. including 17 studies, 1786 cases, and 1574 controls. The authors concluded that the body of evidence to demonstrate a conclusive association between the 14-bp ins/del with the risk of recurrent miscarriages is inadequate (99). In a subgroup analysis, however, they did find an association between the 14-bp ins/del polymorphism and risk of recurrent miscarriage in women, who suffered three or more miscarriages. Furthermore, they criticize the meta-analysis by Wang et al. for including two different studies based on the same study group (99).

An increasing amount of studies acknowledge that the etiology of various pregnancy complications is based on the unique immunogenetic combinations of the mother and the father. Paternal immunogenetic factors may indeed contribute to the risk of development of pre-eclampsia. One study shows that the paternal HLA-G $G^{*} 01: 06$ contribution significantly increases risk for pre-eclampsia in multigravidas, who do not carry this allele (100).

\section{REGULATORY IMMUNE CELLS IN PRE-ECLAMPSIA}

Hsu et al. have recently published a study with the purpose of describing the role of immune regulatory cells in pre-eclamptic women (101). CD4 ${ }^{+} \mathrm{HLA}-\mathrm{G}^{+} \mathrm{T}$ cells in the periphery and the decidua from healthy pregnant women, and from pre-eclamptic cases and non-pregnant women, were measured. In previous studies, APCs characterized by being CD14 ${ }^{+}$DC-SIGN $^{+} \mathrm{HLA}_{-G^{+}}$ and ILT- $4^{+}$have been described. These could be the same DCs described by Gregori et al. (87). Like Tregs, this CD4 ${ }^{+} \mathrm{HLA}_{-G^{+}}$ $\mathrm{T}$ cell subset may play an important role in immune tolerance during pregnancy. In the periphery, increase of $\mathrm{CD}^{+}{ }^{+} \mathrm{HLA}-\mathrm{G}^{+}$ $\mathrm{T}$ cells during healthy pregnancies was observed compared to non-pregnant controls. Pre-eclamptic women had a significantly lower fraction of $\mathrm{CD}^{+}{ }^{+} \mathrm{HLA}-\mathrm{G}^{+}$T cells than healthy pregnant women. $\mathrm{CD}^{+}{ }^{+} \mathrm{HLA}-\mathrm{G}^{+}$T cells seem to be more mature compared to $\mathrm{CD} 4^{+} \mathrm{HLA}_{-\mathrm{G}^{-}} \mathrm{T}$ cells because of their expression of CD80 and CD86. Also, the CD4 ${ }^{+} \mathrm{HLA}_{-\mathrm{G}}{ }^{+}$T cells expand in the decidua compared to the periphery, but whether it is a local expansion of the $\mathrm{T}$ cell pool or recruitment from the periphery is not known. Again, pre-eclamptic women had a lower expansion of $\mathrm{CD}^{+}{ }^{+} \mathrm{HLA}-\mathrm{G}^{+}$ $T$ cells than healthy pregnant women. It was demonstrated that the $\mathrm{CD} 4{ }^{+} \mathrm{HLA}-\mathrm{G}^{+}$T cells acquire their HLA-G by trogocytosis. In this case from $\mathrm{CD}_{14}{ }^{+} \mathrm{DC}-\mathrm{SIGN}{ }^{+}$DCs expressing HLA-G and ILT-4 (101).

\section{FUTURE ASPECTS AND CONCLUSION}

As mentioned, HLA-G exists in a monomer form and a dimer form, the latter by forming an intermolecular disulfide bridge between two cysteine residues of the $\alpha 1$ domains of two HLA$\mathrm{G}$ molecules (102). Studies indicate that the dimer is the most active form; it has a higher affinity than the monomer to ILT-2 and ILT-4, and the dimer enhances the ILT-2-mediated signaling at the cellular level (103). In line with this, focus has been drawn to HLA-G dimers and synthetic dimer HLA-G molecules for possible therapeutic use (104). In mice, recombinant sHLA-G and synthetic HLA-G molecules have been shown to inhibit the early stages of arthritis in a rheumatoid arthritis disease model and to significantly prolong the acceptance of skin grafts $(104,105)$. It can be speculated that synthetic sHLA-G analogs might find a place in the treatment of certain pregnancy-related disorders, such as pre-eclampsia and assisted reproduction. However, a better fundamental understanding of the pathophysiology in these disorders is needed before proceeding to such enterprises.

Also, in in vitro fertilization (IVF) treatments, the measurement of sHLA-G in the embryo culture medium can be used as a marker for improving successful assisted reproductive technology, by choosing the fertilized oocytes with highest potential, as sHLA$\mathrm{G}$ positive culture medium correlates with pregnancy success (10, $58,106)$.

In conclusion, for obtaining a successful conception and a pregnancy in terms of optimized immune modulation, a combined expression of HLA-G from several sources seems to be important: by the mother in the blood, in follicular fluid, and in the genital tract, by the embryo and the trophoblast cells in the placenta, and by the father through the presence of sHLA-G in semen. One of our recent studies even revealed a significant association between HLA-G genotype and the amount of sHLA-G in seminal plasma (16). More studies are needed to elucidate the precise roles and the importance of these different sources of HLA-G in relation to uncomplicated pregnancies and in pre-eclampsia, in recurrent miscarriage and in assisted reproduction, especially with respect to the control of HLA-G expression involving HLA-G gene polymorphisms together with molecular and cellular immune interactions.

\section{ACKNOWLEDGMENTS}

Support for this work was generously provided by grants from the Region Zealand Health Sciences Research Foundation.

\section{REFERENCES}

1. Redman CW, McMichael AJ, Stirrat GM, Sunderland CA, Ting A. Class 1 major histocompatibility complex antigens on human extra-villous trophoblast. Immunology (1984) 52(3):457-68.

2. Kovats S, Main EK, Librach C, Stubblebine M, Fisher SJ, DeMars R. A class I antigen, HLA-G, expressed in human trophoblasts. Science (1990) 248(4952):220-3. doi:10.1126/science.2326636

3. Ellis SA, Palmer MS, McMichael AJ. Human trophoblast and the choriocarcinoma cell line BeWo express a truncated HLA class I molecule. J Immunol (1990) 144(2):731-5.

4. Lee N, Malacko AR, Ishitani A, Chen MC, Bajorath J, Marquardt H, et al. The membrane-bound and soluble forms of HLA-G bind identical sets of endogenous peptides but differ with respect to TAP association. Immunity (1995) 3(5):591-600. doi:10.1016/1074-7613(95)90130-2

5. O’Brien M, McCarthy T, Jenkins D, Paul P, Dausset J, Carosella ED, et al. Altered HLA-G transcription in pre-eclampsia is associated with allele specific inheritance: possible role of the HLA-G gene in susceptibility to the disease. Cell Mol Life Sci (2001) 58(12-13):1943-9. doi:10.1007/PL00000828

6. Hylenius S, Andersen AM, Melbye M, Hviid TV. Association between HLA-G genotype and risk of pre-eclampsia: a case-control study using family triads. Mol Hum Reprod (2004) 10(4):237-46. doi:10.1093/molehr/gah035

7. Larsen MH, Hviid TV. Human leukocyte antigen-G polymorphism in relation to expression, function, and disease. Hum Immunol (2009) 70(12):1026-34. doi:10.1016/j.humimm.2009.07.015

8. Larsen MH, Hylenius S, Andersen AM, Hviid TV. The 3'-untranslated region of the HLA-G gene in relation to pre-eclampsia: revisited. Tissue Antigens (2010) 75(3):253-61. doi:10.1111/j.1399-0039.2009.01435.x 
9. Pfeiffer KA, Rebmann V, van der Ven K. Soluble histocompatibility antigen levels in early pregnancy after IVF. Hum Immunol (2000) 61:559-64. doi:10.1016/S0198-8859(00)00123-3

10. Vercammen MJ, Verloes A, Van de Velde H, Haentjens P. Accuracy of soluble human leukocyte antigen-G for predicting pregnancy among women undergoing infertility treatment: meta-analysis. Hum Reprod Update (2008) 14(3):209-18. doi:10.1093/humupd/dmn007

11. Le Bouteiller P, Pizzato N, Barakonyi A, Solier C. HLA-G, pre-eclampsia, immunity and vascular events. J Reprod Immunol (2003) 59(2):219-34. doi:10.1016/S0165-0378(03)00049-4

12. Hviid TV, Rizzo R, Christiansen OB, Melchiorri L, Lindhard A, Baricordi OR. HLA-G and IL-10 in serum in relation to HLA-G genotype and polymorphisms. Immunogenetics (2004) 56(3):135-41. doi:10.1007/s00251004-0673-2

13. Chen XY, Yan WH, Lin A, Xu HH, Zhang JG, Wang XX. The 14 bp deletion polymorphisms in HLA-G gene play an important role in the expression of soluble HLA-G in plasma. Tissue Antigens (2008) 72(4):335-41. doi:10.1111/j.1399-0039.2008.01107.x

14. Larsen MH, Bzorek M, Pass MB, Larsen LG, Nielsen MW, Svendsen SG, et al. Human leukocyte antigen-G in the male reproductive system and in seminal plasma. Mol Hum Reprod (2011) 17(12):727-38. doi:10.1093/molehr/gar052

15. Thibodeau V, Lajoie J, Labbe AC, Zannou MD, Fowke KR, Alary M, et al. High level of soluble HLA-G in the female genital tract of Beninese commercial sex workers is associated with HIV-1 infection. PLoS One (2011) 6(9):e25185. doi:10.1371/journal.pone.0025185

16. Dahl M, Perin TL, Djurisic S, Rasmussen M, Ohlsson J, Buus S, et al. Soluble human leukocyte antigen-G in seminal plasma is associated with HLA-G genotype: possible implications for fertility success. Am J Reprod Immunol (2014). doi:10.1111/aji.12251

17. Geraghty DE, Koller BH, Orr HT. A human major histocompatibility complex class I gene that encodes a protein with a shortened cytoplasmic segment. Proc Natl Acad Sci U S A (1987) 84(24):9145-9. doi:10.1073/pnas.84.24.9145

18. Hviid TV, Meldgaard M, Sorensen S, Morling N. Polymorphism of exon 3 of the HLA-G gene. J Reprod Immunol (1997) 35(1):31-42. doi:10.1016/S01650378(97)00051-X

19. Hviid TV. HLA-G in human reproduction: aspects of genetics, function and pregnancy complications. Hum Reprod Update (2006) 12(3):209-32. doi:10.1093/humupd/dmi048

20. Donadi EA, Castelli EC, Arnaiz-Villena A, Roger M, Rey D, Moreau P. Implications of the polymorphism of HLA-G on its function, regulation, evolution and disease association. Cell Mol Life Sci (2011) 68(3):369-95. doi:10.1007/s00018-010-0580-7

21. Ober C, Rosinsky B, Grimsley C, van der Ven K, Robertson A, Runge A. Population genetic studies of HLA-G: allele frequencies and linkage disequilibrium with HLA-A1. J Reprod Immunol (1996) 32(2):111-23. doi:10.1016/S01650378(96)01000-5

22. Ober C, Aldrich C, Rosinsky B, Robertson A, Walker MA, Willadsen S, et al. HLA-G1 protein expression is not essential for fetal survival. Placenta (1998) 19(2-3):127-32. doi:10.1016/S0143-4004(98)90000-5

23. Casro MJ, Morales P, Rojo-Amigo R, Martinez-Laso J, Allende L, Varela P, et al. Homozygous HLA-G*0105N healthy individuals indicate that membraneanchored HLA-G1 molecule is not necessary for survival. Tissue Antigens (2000) 56(3):232-9. doi:10.1034/j.1399-0039.2000.560305.x

24. Le Discorde M, Le Danff C, Moreau P, Rouas-Freiss N, Carosella ED. HLA$\mathrm{G}^{\star} 0105 \mathrm{~N}$ null allele encodes functional HLA-G isoforms. Biol Reprod (2005) 73(2):280-8. doi:10.1095/biolreprod.104.037986

25. Kuersten S, Goodwin EB. The power of the 3' UTR: translational control and development. Nat Rev Genet (2003) 4(8):626-37. doi:10.1038/nrg1125

26. Chu W, Gao J, Murphy WJ, Hunt JS. A candidate interferon-gamma activated site (GAS element) in the HLA-G promoter does not bind nuclear proteins. Hum Immunol (1999) 60(11):1113-8. doi:10.1016/S0198-8859(99) 00091-9

27. Gobin SJ, van den Elsen PJ. Transcriptional regulation of the MHC class Ib genes HLA-E, HLA-F, and HLA-G. Hum Immunol (2000) 61(11):1102-7. doi:10.1016/S0198-8859(00)00198-1

28. Hviid TV, Hylenius S, Rorbye C, Nielsen LG. HLA-G allelic variants are associated with differences in the HLA-G mRNA isoform profile and HLA-G mRNA levels. Immunogenetics (2003) 55(2):63-79. doi:10.1007/s00251-003-0547-z
29. Hviid TV, Sorensen S, Morling N. Polymorphism in the regulatory region located more than 1.1 kilobases 5 ' to the start site of transcription, the promoter region, and exon 1 of the HLA-G gene. Hum Immunol (1999) 60(12):1237-44. doi:10.1016/S0198-8859(99)00130-5

30. Rousseau P, Le Discorde M, Mouillot G, Marcou C, Carosella ED, Moreau P. The 14 bp deletion-insertion polymorphism in the 3' UT region of the HLA-G gene influences HLA-G mRNA stability. Hum Immunol (2003) 64(11):1005-10. doi:10.1016/j.humimm.2003.08.347

31. Harrison GA, Humphrey KE, Jakobsen IB, Cooper DW. A 14 bp deletion polymorphism in the HLA-G gene. Hum Mol Genet (1993) 2(12):2200. doi:10.1093/hmg/2.12.2200-a

32. Ober C, Aldrich CL, Chervoneva I, Billstrand C, Rahimov F, Gray HL, et al. Variation in the HLA-G promoter region influences miscarriage rates. Am J Hum Genet (2003) 72(6):1425-35. doi:10.1086/375501

33. Castelli EC, Mendes-Junior CT, Veiga-Castelli LC, Roger M, Moreau P, Donadi EA. A comprehensive study of polymorphic sites along the HLA-G gene: implication for gene regulation and evolution. Mol Biol Evol (2011) 28(11):3069-86. doi:10.1093/molbev/msr138

34. da Silva JS, Slowik R, Bicalho Mda G. Considerations on regulatory sequences of the distal promoter region of the HLA-G gene. Hum Immunol (2013) 74(4):473-7. doi:10.1016/j.humimm.2012.11.027

35. Tan Z, Shon AM, Ober C. Evidence of balancing selection at the HLA-G promoter region. Hum Mol Genet (2005) 14(23):3619-28. doi:10.1093/hmg/ ddi389

36. Ober C, Billstrand C, Kuldanek S, Tan Z. The miscarriage-associated HLA-G -725G allele influences transcription rates in JEG-3 cells. Hum Reprod (2006) 21(7):1743-8. doi:10.1093/humrep/del036

37. Nicolae D, Cox NJ, Lester LA, Schneider D, Tan Z, Billstrand C, et al. Fine mapping and positional candidate studies identify HLA-G as an asthma susceptibility gene on chromosome 6p21. Am J Hum Genet (2005) 76(2):349-57. doi:10.1086/427763

38. Kim SK, Hong MS, Shin MK, Uhm YK, Chung JH, Lee MH. Promoter polymorphisms of the HLA-G gene, but not the HLA-E and HLA-F genes, is associated with non-segmental vitiligo patients in the Korean population. Arch Dermatol Res (2011) 303(9):679-84. doi:10.1007/s00403-011-1160-x

39. Misra MK, Prakash S, Kapoor R, Pandey SK, Sharma RK, Agrawal S. Association of HLA-G promoter and 14-bp insertion-deletion variants with acute allograft rejection and end-stage renal disease. Tissue Antigens (2013) 82(5):317-26. doi: $10.1111 / \tan .12210$

40. Fujii T, Ishitani A, Geraghty DE. A soluble form of the HLA-G antigen is encoded by a messenger ribonucleic acid containing intron 4. J Immunol (1994) 153(12):5516-24.

41. Hiby SE, King A, Sharkey A, Loke YW. Molecular studies of trophoblast HLA-G: polymorphism, isoforms, imprinting and expression in preimplantation embryo. Tissue Antigens (1999) 53(1):1-13. doi:10.1034/j.1399-0039. 1999.530101.x

42. Svendsen SG, Hantash BM, Zhao L, Faber C, Bzorek M, Nissen MH, et al. The expression and functional activity of membrane-bound human leukocyte antigen-G1 are influenced by the 3'-untranslated region. Hum Immunol (2013) 74(7):818-27. doi:10.1016/j.humimm.2013.03.003

43. Castelli EC, Mendes-Junior CT, Deghaide NH, de Albuquerque RS, Muniz YC, Simoes RT, et al. The genetic structure of 3'untranslated region of the HLAG gene: polymorphisms and haplotypes. Genes Immun (2010) 11(2):134-41. doi:10.1038/gene.2009.74

44. Tan Z, Randall G, Fan J, Camoretti-Mercado B, Brockman-Schneider R, Pan L, et al. Allele-specific targeting of microRNAs to HLA-G and risk of asthma. Am J Hum Genet (2007) 81(4):829-34. doi:10.1086/521200

45. Manaster I, Goldman-Wohl D, Greenfield C, Nachmani D, Tsukerman P, Hamani Y, et al. MiRNA-mediated control of HLA-G expression and function. PLoS One (2012) 7(3):e33395. doi:10.1371/journal.pone.0033395

46. Di Cristofaro J, El Moujally D, Agnel A, Mazieres S, Cortey M, Basire A, et al. HLA-G haplotype structure shows good conservation between different populations and good correlation with high, normal and low soluble HLA-G expression. Hum Immunol (2013) 74(2):203-6. doi:10.1016/j.humimm.2012. 10.027

47. Martelli-Palomino G, Pancotto JA, Muniz YC, Mendes-Junior CT, Castelli EC, Massaro JD, et al. Polymorphic sites at the 3' untranslated region of the HLA-G gene are associated with differential hla-g soluble levels in the Brazilian and 
French population. PLoS One (2013) 8(10):e71742. doi:10.1371/journal.pone. 0071742

48. Auboeuf D, Honig A, Berget SM, O'Malley BW. Coordinate regulation of transcription and splicing by steroid receptor coregulators. Science (2002) 298(5592):416-9. doi:10.1126/science.1073734

49. Ishitani A, Geraghty DE. Alternative splicing of HLA-G transcripts yields proteins with primary structures resembling both class I and class II antigens. Proc Natl Acad Sci U S A (1992) 89(9):3947-51. doi:10.1073/pnas.89.9.3947

50. Hviid TV, Moller C, Sorensen S, Morling N. Co-dominant expression of the HLA-G gene and various forms of alternatively spliced HLA-G mRNA in human first trimester trophoblast. Hum Immunol (1998) 59(2):87-98. doi:10.1016/S0198-8859(97)00259-0

51. Davis DM, Reyburn HT, Pazmany L, Chiu I, Mandelboim O, Strominger JL. Impaired spontaneous endocytosis of HLA-G. Eur J Immunol (1997) 27(10):2714-9. doi:10.1002/eji.1830271035

52. Park B, Lee S, Kim E, Chang S, Jin M, Ahn K. The truncated cytoplasmic tail of HLA-G serves a quality-control function in post-ER compartments. Immunity (2001) 15(2):213-24. doi:10.1016/S1074-7613(01)00179-0

53. Park GM, Lee S, Park B, Kim E, Shin J, Cho K, et al. Soluble HLA-G generated by proteolytic shedding inhibits NK-mediated cell lysis. Biochem Biophys Res Commun (2004) 313(3):606-11. doi:10.1016/j.bbrc.2003.11.153

54. Rizzo R, Dal Canto MB, Stignani M, Fadini R, Fumagalli D, Renzini MM, et al. Production of sHLA-G molecules by in vitro matured cumulus-oocyte complex. Int J Mol Med (2009) 24:523-30. doi:10.3892/ijmm_00000261

55. Shaikly VR, Morrison IE, Taranissi M, Noble CV, Withey AD, Cherry RJ, et al. Analysis of HLA-G in maternal plasma, follicular fluid, and preimplantation embryos reveal an asymmetric pattern of expression. J Immunol (2008) 180(6):4330-7. doi:10.4049/jimmunol.180.6.4330

56. Langat DK, Sue Platt J, Tawfik O, Fazleabas AT, Hunt JS. Differential expression of human leukocyte antigen-G (HLA-G) messenger RNAs and proteins in normal human prostate and prostatic adenocarcinoma. J Reprod Immunol (2006) 71(1):75-86. doi:10.1016/j.jri.2006.01.006

57. Jurisicova A, Casper RF, MacLusky NJ, Mills GB, Librach CL. HLA-G expression during preimplantation human embryo development. Proc Natl Acad Sci U S A (1996) 93(1):161-5. doi:10.1073/pnas.93.1.161

58. Fuzzi B, Rizzo R, Criscuoli L, Noci I, Melchiorri L, Scarselli B, et al. HLA$\mathrm{G}$ expression in early embryos is a fundamental prerequisite for the obtainment of pregnancy. Eur J Immunol (2002) 32(2):311-5. doi:10.1002/15214141(200202)32:2<311::AID-IMMU311>3.0.CO;2-8

59. Crisa L, McMaster MT, Ishii JK, Fisher SJ, Salomon DR. Identification of a thymic epithelial cell subset sharing expression of the class Ib HLA-G molecule with fetal trophoblasts. J Exp Med (1997) 186(2):289-98. doi:10.1084/jem.186. 2.289

60. Le Discorde M, Moreau P, Sabatier P, Legeais JM, Carosella ED. Expression of HLA-G in human cornea, an immune-privileged tissue. Hum Immunol (2003) 64(11):1039-44. doi:10.1016/j.humimm.2003.08.346

61. Steinborn A, Rebmann V, Scharf A, Sohn C, Grosse-Wilde H. Placental abruption is associated with decreased maternal plasma levels of soluble HLA-G. J Clin Immunol (2003) 23(4):307-14. doi:10.1023/A:1024592901663

62. Yie SM, Li LH, Li YM, Librach C. HLA-G protein concentrations in maternal serum and placental tissue are decreased in preeclampsia. Am J Obstet Gynecol (2004) 191(2):525-9. doi:10.1016/j.ajog.2004.01.033

63. Rebmann V, Busemann A, Lindemann M, Grosse-Wilde H. Detection of HLAG5 secreting cells. Hum Immunol (2003) 64:1017-24. doi:10.1016/j.humimm. 2003.08.354

64. Dahl M, Hviid TV. Human leucocyte antigen class Ib molecules in pregnancy success and early pregnancy loss. Hum Reprod Update (2012) 18:92-109. doi:10.1093/humupd/dmr043

65. Ishitani A, Sageshima N, Lee N, Dorofeeva N, Hatake K, Marquardt H, et al. Protein expression and peptide binding suggest unique and interacting functional roles for HLA-E, F, and G in maternal-placental immune recognition. J Immunol (2003) 171(3):1376-84. doi:10.4049/jimmunol.171.3. 1376

66. Sargent IL. Does "soluble" HLA-G really exist? Another twist to the tale. Mol Hum Reprod (2005) 11(10):695-8. doi:10.1093/molehr/gah196

67. Hunt JS, Jadhav L, Chu W, Geraghty DE, Ober C. Soluble HLA-G circulates in maternal blood during pregnancy. Am J Obstet Gynecol (2000) 183(3):682-8. doi:10.1067/mob.2000.106762
68. Zhu Y, Huo Z, Lai J, Li S, Jiao H, Dang J, et al. Case-control study of a HLA-G 14bp insertion-deletion polymorphism in women with recurrent miscarriages. Scand J Immunol (2010) 71(1):52-4. doi:10.1111/j.1365-3083.2009.02348.x

69. Lopez AS, Alegre E, LeMaoult J, Carosella E, Gonzalez A. Regulatory role of tryptophan degradation pathway in HLA-G expression by human monocytederived dendritic cells. Mol Immunol (2006) 43(14):2151-60. doi:10.1016/j. molimm.2006.01.007

70. Munn DH, Zhou M, Attwood JT, Bondarev I, Conway SJ, Marshall B, et al. Prevention of allogeneic fetal rejection by tryptophan catabolism. Science (1998) 281(5380):1191-3. doi:10.1126/science.281.5380.1191

71. LeMaoult J, Caumartin J, Daouya M, Favier B, Le Rond S, Gonzalez A, et al. Immune regulation by pretenders: cell-to-cell transfers of HLA-G make effector T cells act as regulatory cells. Blood (2007) 109(5):2040-8. doi:10.1182/ blood-2006-05-024547

72. Rouas-Freiss N, Marchal RE, Kirszenbaum M, Dausset J, Carosella ED. The alpha1 domain of HLA-G1 and HLA-G2 inhibits cytotoxicity induced by natural killer cells: is HLA-G the public ligand for natural killer cell inhibitory receptors? Proc Natl Acad Sci U S A (1997) 94(10):5249-54. doi:10.1073/pnas. 94.10.5249

73. Amodio G, Gregori S. Human tolerogenic DC-10: perspectives for clinical applications. Transplant Res (2012) 1(1):14. doi:10.1186/2047-1440-1-14

74. Rajagopalan S, Long EO. A human histocompatibility leukocyte antigen (HLA)-G-specific receptor expressed on all natural killer cells. J Exp Med (1999) 189(7):1093-100. doi:10.1084/jem.189.7.1093

75. Le Page ME, Goodridge JP, John E, Christiansen FT, Witt CS. Killer Ig-like receptor 2DL4 does not mediate NK cell IFN-gamma responses to soluble HLAG preparations. J Immunol (2014) 192(2):732-40. doi:10.4049/jimmunol. 1301748

76. Rajagopalan S, Long EO. KIR2DL4 (CD158d): an activation receptor for HLAG. Front Immunol (2012) 3:258. doi:10.3389/fimmu.2012.00258

77. Shiroishi M, Tsumoto K, Amano K, Shirakihara Y, Colonna M, Braud VM, et al. Human inhibitory receptors Ig-like transcript 2 (ILT2) and ILT4 compete with CD8 for MHC class I binding and bind preferentially to HLAG. Proc Natl Acad Sci U S A (2003) 100(15):8856-61. doi:10.1073/pnas. 1431057100

78. Shiroishi M, Kuroki K, Rasubala L, Tsumoto K, Kumagai I, Kurimoto E, et al. Structural basis for recognition of the nonclassical MHC molecule HLA-G by the leukocyte Ig-like receptor B2 (LILRB2/LIR2/ILT4/CD85d). Proc Natl Acad Sci U S A (2006) 103(44):16412-7. doi:10.1073/pnas.0605228103

79. LeMaoult J, Zafaranloo K, Le Danff C, Carosella ED. HLA-G up-regulates ILT2, ILT3, ILT4, and KIR2DL4 in antigen presenting cells, NK cells, and T cells. FASEB J (2005) 19(6):662-4. doi:10.1096/fj.04-1617fje

80. Fournel S, Aguerre-Girr M, Huc X, Lenfant F, Alam A, Toubert A, et al. Cutting edge: soluble HLA-G1 triggers CD95/CD95 ligand-mediated apoptosis in activated CD8+ cells by interacting with CD8. J Immunol (2000) 164(12):6100-4. doi:10.4049/jimmunol.164.12.6100

81. Koopman LA, Kopcow HD, Rybalov B, Boyson JE, Orange JS, Schatz F, et al. Human decidual natural killer cells are a unique NK cell subset with immunomodulatory potential. JExp Med (2003) 198(8):1201-12. doi:10.1084/ jem.20030305

82. Leonard S, Murrant C, Tayade C, van den Heuvel M, Watering R, Croy BA. Mechanisms regulating immune cell contributions to spiral artery modification - facts and hypotheses - a review. Placenta (2006) 27(Suppl A):S40-6. doi:10.1016/j.placenta.2005.11.007

83. Gros F, Cabillic F, Toutirais O, Maux AL, Sebti Y, Amiot L. Soluble HLA-G molecules impair natural killer/dendritic cell crosstalk via inhibition of dendritic cells. Eur J Immunol (2008) 38(3):742-9. doi:10.1002/eji.200736918

84. Llano M, Lee N, Navarro F, Garcia P, Albar JP, Geraghty DE, et al. HLA-E-bound peptides influence recognition by inhibitory and triggering CD94/NKG2 receptors: preferential response to an HLA-G-derived nonamer. Eur J Immunol (1998) 28(9):2854-63. doi:10.1002/(SICI)1521-4141(199809) 28:09<2854::AID-IMMU2854>3.0.CO;2-W

85. Gregori S, Tomasoni D, Pacciani V, Scirpoli M, Battaglia M, Magnani CF, et al. Differentiation of type $1 \mathrm{~T}$ regulatory cells $(\mathrm{Tr} 1)$ by tolerogenic DC-10 requires the IL-10-dependent ILT4/HLA-G pathway. Blood (2010) 116(6):935-44. doi:10.1182/blood-2009-07-234872

86. Du MR, Guo PF, Piao HL, Wang SC, Sun C, Jin LP, et al. Embryonic trophoblasts induce decidual regulatory $\mathrm{T}$ cell differentiation and maternal-fetal tolerance 
through thymic stromal lymphopoietin instructing dendritic cells. J Immunol (2014) 192(4):1502-11. doi:10.4049/jimmunol.1203425

87. Amodio G, Mugione A, Sanchez AM, Vigano P, Candiani M, Somigliana E, et al. HLA-G expressing DC-10 and CD4(+) T cells accumulate in human decidua during pregnancy. Hum Immunol (2013) 74(4):406-11. doi:10.1016/ j.humimm.2012.11.031

88. Aluvihare VR, Kallikourdis M, Betz AG. Regulatory T cells mediate maternal tolerance to the fetus. Nat Immunol (2004) 5(3):266-71. doi:10.1038/ni1037

89. Moreau P, Contu L, Alba F, Lai S, Simoes R, Orru S, et al. HLA-G gene polymorphism in human placentas: possible association of $\mathrm{G}^{\star} 0106$ allele with preeclampsia and miscarriage. Biol Reprod (2008) 79:459-67. doi:10.1095/ biolreprod.108.068874

90. Zhang Z, Li Y, Zhang LL, Jia LT, Yang XQ. Association of 14 bp insertion/ deletion polymorphism of the HLA-G gene in father with severe preeclampsia in Chinese. Tissue Antigens (2012) 80:158-64. doi:10.1111/j.1399-0039.2012. 01907.x

91. Bermingham J, Jenkins D, McCarthy T, O'Brien M. Genetic analysis of insulinlike growth factor II and HLA-G in pre-eclampsia. Biochem Soc Trans (2000) 28(2):215-9. doi:10.1042/bst0280215

92. Vianna P, Dalmaz CA, Veit TD, Tedoldi C, Roisenberg I, Chies JA. Immunogenetics of pregnancy: role of a 14-bp deletion in the maternal HLA-G gene in primiparous pre-eclamptic Brazilian women. Hum Immunol (2007) 68(8):668-74. doi:10.1016/j.humimm.2007.05.006

93. Iversen AC, Nguyen OT, Tommerdal LF, Eide IP, Landsem VM, Acar N, et al. The HLA-G 14bp gene polymorphism and decidual HLA-G 14bp gene expression in pre-eclamptic and normal pregnancies. J Reprod Immunol (2008) 78(2):158-65. doi:10.1016/j.jri.2008.03.001

94. Redman CW, Sargent IL. Placental debris, oxidative stress and pre-eclampsia. Placenta (2000) 21:597-602. doi:10.1053/plac.2000.0560

95. Yie SM, Li LH, Xiao R, Librach CL. A single base-pair mutation in the 3'untranslated region of HLA-G mRNA is associated with pre-eclampsia. Mol Hum Reprod (2008) 14(11):649-53. doi:10.1093/molehr/gan059

96. Aldrich CL, Stephenson MD, Karrison T, Odem RR, Branch DW, Scott JR, et al. HLA-G genotypes and pregnancy outcome in couples with unexplained recurrent miscarriage. Mol Hum Reprod (2001) 7(12):1167-72. doi:10.1093/ molehr/7.12.1167

97. Hviid TV, Hylenius S, Hoegh AM, Kruse C, Christiansen OB. HLA-G polymorphisms in couples with recurrent spontaneous abortions. Tissue Antigens (2002) 60(2):122-32. doi:10.1034/j.1399-0039.2002.600202.x

98. Wang X, Jiang W, Zhang D. Association of 14-bp insertion/deletion polymorphism of HLA-G gene with unexplained recurrent spontaneous abortion: a meta-analysis. Tissue Antigens (2013) 81(2):108-15. doi:10.1111/tan.12056

99. Fan W, Li S, Huang Z, Chen Q. Relationship between HLA-G polymorphism and susceptibility to recurrent miscarriage: a meta-analysis of non-family-based studies. J Assist Reprod Genet (2014) 31(2):173-84. doi:10. 1007/s10815-013-0155-2

100. Tan CY, Ho JF, Chong YS, Loganath A, Chan YH, Ravichandran J, et al. Paternal contribution of HLA-G*0106 significantly increases risk for preeclampsia in multigravid pregnancies. Mol Hum Reprod (2008) 14(5):317-24. doi:10.1093/molehr/gan013

101. Hsu P, Santner-Nanan B, Joung S, Peek MJ, Nanan R. Expansion of CD4(+) HLA-G(+) T cell in human pregnancy is impaired in pre-eclampsia. Am J Reprod Immunol (2014) 71(3):217-28. doi:10.1111/aji.12195

102. Apps R, Gardner L, Sharkey AM, Holmes N, Moffett A. A homodimeric complex of HLA-G on normal trophoblast cells modulates antigen-presenting cells via LILRB1. Eur J Immunol (2007) 37(7):1924-37. doi:10.1002/eji.200737089

103. Shiroishi M, Kuroki K, Ose T, Rasubala L, Shiratori I, Arase H, et al. Efficient leukocyte Ig-like receptor signaling and crystal structure of disulfidelinked HLA-G dimer. J Biol Chem (2006) 281(15):10439-47. doi:10.1074/jbc. M603076200

104. LeMaoult J, Daouya M, Wu J, Loustau M, Horuzsko A, Carosella ED. Synthetic HLA-G proteins for therapeutic use in transplantation. FASEB J (2013) 27(9):3643-51. doi:10.1096/fj.13-228247

105. Kuroki K, Hirose K, Okabe Y, Fukunaga Y, Takahashi A, Shiroishi M, et al. The long-term immunosuppressive effects of disulfide-linked HLA-G dimer in mice with collagen-induced arthritis. Hum Immunol (2013) 74(4):433-8. doi:10.1016/j.humimm.2012.11.060

106. Kotze D, Kruger TF, Lombard C, Padayachee T, Keskintepe L, Sher G. The effect of the biochemical marker soluble human leukocyte antigen $\mathrm{G}$ on pregnancy outcome in assisted reproductive technology - a multicenter study. Fertil Steril (2013) 100(5):1303-9. doi:10.1016/j.fertnstert.2013.07.1977

Conflict of Interest Statement: The authors declare that the research was conducted in the absence of any commercial or financial relationships that could be construed as a potential conflict of interest.

Received: 01 March 2014; accepted: 22 April 2014; published online: 13 May 2014. Citation: Lynge Nilsson L, Djurisic S and Hviid TVF (2014) Controlling the immunological crosstalk during conception and pregnancy: HLA-G in reproduction. Front. Immunol. 5:198. doi: 10.3389/fimmu.2014.00198

This article was submitted to Inflammation, a section of the journal Frontiers in Immunology.

Copyright $\odot 2014$ Lynge Nilsson, Djurisic and Hviid. This is an open-access article distributed under the terms of the Creative Commons Attribution License (CC BY). The use, distribution or reproduction in other forums is permitted, provided the original author(s) or licensor are credited and that the original publication in this journal is cited, in accordance with accepted academic practice. No use, distribution or reproduction is permitted which does not comply with these terms. 